\title{
Células-Tronco Mesenquimais para Reparo Cardíaco
}

\author{
Michael D. Schuster ${ }^{1}$, Timothy P. Martens ${ }^{1}$, Silviu Itescu'
}

\section{RESUMO}

As células-tronco mesenquimais (CTMs) são uma população adulta de células que compartilham algumas características fenotípicas com as células-tronco embrionárias, mas carecem da preocupação ética ou da segurança associadas a tais células indiferenciadas. As CTMs estão localizadas, principalmente, na medula óssea e, em menor grau, em outros tecidos. Elas podem ser positivamente selecionadas, expandidas em cultura ex vivo, e se diferenciar para a linhagem de osteócitos, condrócitos e adipócitos do tecido mesenquimal. As chamadas células mesenquimais progenitoras (CMPs), precursoras de CTMs, podem ser isoladas da medula óssea, resultando em produto homogêneo, contendo uma população marcadamente mais pura de CTMs, ou seja, sem o elevado número de células contaminantes inerentes às técnicas de isolamento. Além disso, as CTMs carecem de certos receptores coestimulantes, como os antígenos de histocompatibilidade (HLA) da classe II, e, localmente, secretam fatores, diminuindo a resposta das células $\mathrm{T}$ e permitindo a utilização alogênica como produto já disponível. As CTMs aumentaram a neovascularização e a regeneração de cardiomiócitos em uma série de modelos animais, acarretando a melhoria do resultado funcional cardíaco e a limitação do progresso da insuficiência cardíaca. $\mathrm{O}(\mathrm{s})$ mecanismo(s) de melhoria permanece $(m)$ um assunto discutível. As alternativas incluem diferenciação direta das CTMs versus secreção parácrina de fatores que indiretamente afetam o tecido endógeno e as células progenitoras locais. Apesar de ainda se buscar o mecanismo exato da melhoria cardíaca, fica claro que as CTMs alogênicas oferecem terapia celular reprodutível, barata e amigável, do ponto de vista regulatório, para o tratamento de moléstia cardiovascular, que, para maior segurança e eficiência, precisarão ser investigadas por ensaios clínicos.

DESCRITORES: Células-tronco. Terapia tissular. Isquemia miocárdica. Miocárdio.
SUMMARY

\author{
Allogeneic Mesenchymal Stem Cells \\ for Cardiac Repair
}

Mesenchymal stem cells (MSCs) are an adult stem cell population that share some phenotypic characteristics with embryonic stem cells but lack the ethical or safety concerns associated with such undifferentiated cells. MSCs are located primarily in the bone marrow and to a lesser extent other tissues and can be positively selected, ex vivo culture expanded and are able to differentiate into the mesenchymal tissue lineage of osteocytes, chondrocytes and adipocytes. A precursor of MSCs termed mesenchymal progenitor cells (MPCs) can be further isolated from bone marrow resulting in a homogenous product containing a significantly purer population of MSCs without the high number of contaminating cells inherent toMSC isolation techniques. Additionally, MSCs lack certain co-stimulatory receptors such as HLA class II and locally secrete factors downregulating T cell responses allowing for allogeneic usage as an off-the-shelf product. MSCs increase neovascularization and cardiomyocyte regeneration in a number of animal models resulting in improvement in cardiac functional outcome and limitation of the progression to heart failure. The mechanism(s) of improvement remains a matter of debate. Alternatives include direct differentiation of the MSCs vs. paracrine secretion of factors that indirectly effect endogenous tissue and local progenitor cells. While the exact mechanism of cardiac improvement continues to be explored, it is clear that allogeneic MSCs offer a reproducible, inexpensive, regulatory-friendly cellular therapy treatment for cardiovascular disease that will need to be investigated in larger safety and efficacy clinical trials.

DESCRIPTORS: Stem cells. Tissue therapy. Myocardial ischemia. Myocardium.
Columbia University, Department of Surgery - New York, NY, Estados Unidos.

Correspondência: Michael Schuster. Angioblast Systems, Inc. - 275 Madison Ave. 4th floor - New York, NY, USA - 10016

Tel.: 1-212-880-2060 • Fax: 1-212-880-2061

E-mail: michael.schuster@angioblast.com

Recebido em: 20/1/2007 • Aceito em: 8/11/2007
A o longo da última década, o crescimento considerável no campo da biologia do desenvolvimento e da biologia vascular levou à descoberta de múltiplos tipos de células, com potencial de ajudar na angiogênese, na miogênese ou em ambas. As células, de maneira geral, podem ser classificadas em dois 
grupos: adultas e embrionárias. Potencialmente, cada tipo de célula examinado comprovou sua eficácia em modelos animais, apesar de, muitas vezes, os mecanismos exatos subjacentes à recuperação funcional serem pouco claros. Todavia, os resultados de estudos pré-clínicos vêm servindo de base para justificar os ensaios clínicos incipientes, tanto nos quadros agudos como nos quadros crônicos.

Durante a fase inicial do desenvolvimento embrionário, especificamente nos primeiros oito dias após a fertilização, existe uma esfera cheia de líquido cujas paredes são compostas por uma única camada de células circundando a cavidade. Os períodos de blástula contêm, aproximadamente, 200 a 250 células-tronco embrionárias pluripotentes, que formam os blocos de construção para toda a futura diferenciação e especialização dos tecidos'. Essa pluripotência tem enorme potencial clínico, e protocolos in vitro, tanto para miogênese como para vasculogênese, foram publicados por diversos laboratórios. Contudo, a pluripotência tem um preço, pois há uma série de questões de segurança relativas à tumorgenicidade e à incapacidade de controlar a diferenciação in vivo das célulastronco embrionárias². Dessa forma, é provável que algum nível de diferenciação ex vivo seja necessário para provocar resposta imune e potencialmente levar à rejeição. Juntas, essas barreiras fundamentais tornam o uso terapêutico das células-tronco embrionárias pouco provável em futuro próximo.

Considerando-se que as células-tronco adultas contêm a maioria das características fenotípicas das células-tronco embrionárias, embora careçam de algumas de suas qualidades negativas, elas representam a modalidade clínica inicial mais provável para aplicações terapêuticas celulares difundidas das célulastronco. As células-tronco adultas têm sido usadas atualmente em uma pletora de ensaios clínicos, em decorrência de sua maior facilidade de obtenção, da eficácia comprovada em modelos pré-clínicos e do perfil claramente seguro. Células-tronco adultas derivadas da medula óssea podem ser categorizadas em dois segmentos: hematopoiéticas e células-tronco mesenquimais (CTMs). O microambiente da medula óssea constitui uma combinação de células-tronco hematopoiéticas combinadas com a rede de células do estroma do tecido conectivo, junto com o processo regulatório da hematopoiese ${ }^{3}$.

Atualmente, é essa população de células-tronco que está sendo usada para tratar de certas anemias e leucemias após quimioterapia ablativa ${ }^{4}$. Essa população mononuclear/hematopoiética também foi aplicada em estudos clínicos com resultados promissores ${ }^{5}$.

A otimização continuada da retenção celular e o aperfeiçoamento dos métodos de administração podem aumentar ainda mais os benefícios funcionais conseguidos com esse tipo de células. Todavia, pelos motivos detalhados na discussão a seguir, é a linha- gem de CTMs que oferece a maior promessa para tratamento da moléstia cardiovascular.

\section{Células-tronco mesenquimais}

As CTMs, descobertas pela primeira vez na medula óssea por Friedenstein et al. ${ }^{6}$, foram caracterizadas por sua capacidade de formar colônias aderentes in vitro, que, fenotipicamente, se parecem a fibroblastos (unidades formadoras de colônias de fibroblasto - CFUFs). Na medula óssea adulta, a freqüência de CFU-Fs clonogênicas varia de $1-20 \times 10^{5}$ células mononucleares e são heterogêneas em tamanho, morfologia, proliferação e potencial de diferenciação ${ }^{7}$. As CTMs localizam-se principalmente na medula óssea, mas também podem ser encontradas em outros tecidos, como gordura, polpa dentária, pele e, em menor grau, nas extremidades encapsuladas dos nervos sensoriais. Metodologias grosseiras para isolar tais células progenitoras envolvem protocolos de centrifugação em gradiente de densidade de Percoll, seguidos por aderência plástica ${ }^{8}$. Contudo, isso resulta em grande número de monócitos e fibroblastos contaminantes, que reprimem o verdadeiro potencial de crescimento da CTM, com conseqüente excrescência de CTMs irregulares e pouco controladas.

As CTMs têm a capacidade de se diferenciar em osteócitos, condriócitos, adipócitos e outros tecidos derivados da camada mesenquimal, durante o desenvolvimento inicial ${ }^{8,9}$. Algumas evidências endossam a capacidade de as CTMs se diferenciarem em uma linhagem de células ectodérmicas, bem como expressarem genes e proteínas de superfície representantes de células do músculo liso e cardiomiócitos, tanto in vitro como in vivo ${ }^{10}$. O maior problema com a expansão da cultura mesenquimal é sua dependência do soro fetal bovino (SFB), que induz o fator de confusão da variabilidade lote por lote ${ }^{11}$. Isso, associado ao medo de transmissão de doença bovina e à limitada reserva de SFB, sem dúvida resultará em investigação continuada para alternativas isentas de soro. A composição exata de citoquinas que resultam no crescimento máximo de CTMs não diferenciadas nem transformadas, enquanto preservam as anomalias cromossômicas das células de passagem tardia observada com CTMs expandidas em cultura com SFB, continua desconhecida.

\section{Identificação das células-tronco mesenquimais}

A popularização das células-tronco, inclusive no vernáculo, criou certa confusão, até mesmo na comunidade científica, a respeito da definição de CTMs e de células-tronco mesenquimais progenitoras. Esses termos, às vezes, são confundidos com as células mononucleares inteiras da medula óssea, embora essa população contenha apenas uma minoria de CTMs (1/1.000 das células sendo células progenitoras 
pluripotentes verdadeiras) ${ }^{7}$. Há vários marcadores protéicos de superfície que podem vagamente definir as CTMs. Especificamente, o marcador hematopoiético CD45 falta nessas células; todavia, até isso depende do método de isolamento e das condições de crescimento da cultura ${ }^{8}$. Por si, a identificação de marcador de superfície não basta para identificar CTMs. Os marcadores precisam ser associados a ensaios de potência funcional in vitro ou in vivo para correlacionar os resultados com o perfil de superfície, porque mesmo modificações insignificantes dos processos podem resultar em seleção e desenvolvimento de uma população indesejada.

Recentemente, uma população minimamente diferente de células-tronco foi identificada com a utilização de estratégias de seleção negativa, resultando em células progenitoras adultas multipotentes capazes de efetuar a diferenciação entre linhagens mesenquimais, endodérmicas e ectodérmicas ${ }^{12,13}$. Essas células parecem ter potencial indefinido de expansão; contudo, uma série de fatores limita seu uso clínico. Entre esses fatores, incluem-se presença extremamente baixa na medula óssea, dificuldade de separação, variabilidade entre lotes, e elevado número de duplicações da população para atingir quantidades terapêuticas. Por esses motivos, sob a perspectiva científica, embora as células progenitoras adultas multipotentes sejam intrigantes, é pouco provável que tenham aplicação clínica em futuro próximo.

Outras estratégias utilizaram imunosseleção com anticorpos monoclonais (mAbs), como STROI-1 ou mAbs, que reconhecem especificamente as células mesenquimais precursoras. Métodos secundários marcados por via magnética são então capazes de selecionar somente essa população de interesse, resultando na disseminação de uma população de células progenitoras mesenquimais homogênea e pura ${ }^{7,11}$. Essa uniformidade é crítica para a reprodutibilidade e a consistência da eficácia lote a lote. As células mesenquimais progenitoras selecionadas dessa forma estão anatomicamente localizadas em nichos perivasculares na medula óssea e por todo o corpo, exibem identidade fenotípica e genética com os pericitos vasculares, e, quando expandidas ex vivo, são capazes de formar CFU-Fs do tipo fibroblastóide e de se diferenciar em músculo liso, osso, cartilagem e tecido adiposo ${ }^{14}$. Em contraste às CTMs, as células mesenquimais progenitoras retêm na cultura seu estado desdiferenciado, porém são facilmente dilatáveis, ao contrário das células progenitoras adultas multipotentes, fazendo das células mesenquimais progenitoras um tipo de célula muito promissor para aplicações terapêuticas.

\section{Células-tronco alogênicas}

A terapia com células-tronco autólogas traz uma série de graves desvantagens. Primeiro, em geral, a fonte de células é um paciente com doença já existente $^{15}$. Esse paciente pode estar instável demais para extrair as células de interesse, além de poder ter rendimento inferior, com número maior de células comprometidas em decorrência da idade avançada. Adicionalmente, etapas de imunosseleção restringem o número de células disponíveis para uso imediato, muitas vezes sendo necessárias semanas de manipulação/ expansão ex vivo para chegar a quantidades terapêuticas. Mesmo em mãos experientes, coloração Gram com resultado falso positivo ou contaminação real da cultura podem fazer com que o produto expandido não seja utilizável. Os custos de tal processo e a impossibilidade de aumentar a produção combinada com barreiras de regulamentação, associados à eficácia inconstante do produto, tornam o desenvolvimento de um produto autólogo indesejável.

Hoje em dia, existem evidências endossando a natureza imunoprivilegiada e imunossupressora das CTMs. Esse efeito foi primeiramente observado na ausência de rejeição, quando CTMs geneticamente modificadas eram transplantadas em babuínos ${ }^{16}$. No homem, as CTMs foram usadas com sucesso para tratar moléstia aguda de enxerto-para-hospedeiro após transplante de célulastronco alogênicas. A Osiris Therapeutics, empresa americana especializada no desenvolvimento e na comercialização de terapias celulares baseadas em célulastronco, está atualmente completando seu estudo clínico de fase III, buscando aprovação jurídica para essa indicação ${ }^{17}$. O mecanismo exato pelo qual as CTMs escapam de reconhecimento imune permanece pouco claro. As CTMs são capazes de inibir a proliferação de células $\mathrm{T}$ alo-reativas in vitro e podem até suprimir a proliferação de células $T$ na reação linfocitária mista de terceiros ${ }^{18}$. Uma das propriedades únicas imunofenotípicas das CTMs é a falta de certas moléculas coestimuladoras, como os antígenos de histocompatibilidade (HLA) classe II, CD40L e CTLA-4 ${ }^{19}$. Essa característica não parece demandar dependência de contato, nem indução direta de apoptose de células T. É mais provável que resulte da secreção parácrina de fatores como fator de crescimento tumoral-beta (TGFbeta) ou fator de crescimento de hepatócito (HGF), criando redução local celular do número de componentes de imunorreconhecimento/resposta ${ }^{20}$.

As CTMs oferecem, portanto, potencial para serem usadas como produto já pronto, que pode ser administrado para pacientes que não combinam geneticamente, sem necessidade de terapia imunossupressora. Isso permite a criação de um banco de células mestras de jovens voluntários saudáveis, com células-tronco robustas, as quais podem ser perfeitamente caracterizadas, processadas de forma uniforme e validadas para segurança e potência antes de serem administradas ao homem. Em tese, as células-tronco de um doador podem ser expandidas, em cultura, para grandes números, podendo ser usadas para tratar milhares de pacientes sem alterar as propriedades das CTMs, o que resulta em preço baixo, retorno semelhante ao dos produtos farmacêuticos, segurança e facilidade de uso. 


\section{Células-tronco mesenquimais para reparo cardíaco}

Após infarto do miocárdio, embora tente compensar, o coração não consegue atender às necessidades do peri-infarto e dos cardiomiócitos hipertrofiados, resultando em apoptose e expansão da área infartada inicial $^{21,22}$. Enquanto o coração tem, até certo ponto, a capacidade de regenerar cardiomiócitos, seja por causa da mobilização das células progenitoras vindas da medula óssea, migrando para o coração isquêmico (células-tronco cardíacas residentes), seja por efeitos indiretos da angiogênese induzida pela citocina pósinfarto, os resultados são insuficientes para alterar o processo de remodelamento ${ }^{23}$. Portanto, foi proposto que a administração exógena de células-tronco progenitoras pode ser capaz de ultrapassar esse limiar e, junto com a resposta endógena pós-sobrevida pósinfarto, reparar os cardiomiócitos danificados e despertar o miocárdio hibernado.

Nem todas as células progenitoras, porém, induzem o efeito desejado. Mioblastos esqueléticos, apesar de capazes de se implantar com sucesso no coração, não foram capazes de se diferenciar em cardiomiócitos; ao contrário, reverteram-se para sua forma combinada de miócitos esqueléticos ${ }^{24}$. Esse nãopareamento dos tecidos pode levar a diferenças fundamentais na condução elétrica, resultando na maior incidência de arritmia observada em estudos humanos. Os ensaios clínicos investigando terapia autóloga com mioblastos esqueléticos em pacientes submetidos a cirurgia de revascularização miocárdica foram interrompidos por falta de eficiência, somada à preocupação relativa à segurança em potencial durante o retardo na revascularização, necessário para o processo de crescimento autólogo. Em contraste, há crescente evidência sugerindo que as CTMs são capazes de melhorar a função cardíaca em modelos animais, de porte tanto pequeno como grande, após infarto do miocárdio. O mecanismo exato subjacente a esses efeitos, porém, continua indefinido ${ }^{25,26}$.

Os primeiros estudos demonstrando potencial terapêutico para a terapia celular em doença cardiovascular empregavam injeção direta da medula óssea inteira no ventrículo esquerdo após crioinjúria ${ }^{27}$. Apesar de usar manipulação de células-tronco com pré-tratamento de 5-azacitidina como agente de desmetilação do DNA para propelir as células ao longo da via dos cardiomiócitos e de ser um modelo de lesão não-fisiológica, demonstrou que, mesmo em uma população heterogênea de células-tronco, poderia induzir melhoria cardíaca limitada. Desde então, os pesquisadores têm dirigido seu foco para populações mais homogêneas e bem definidas de células progenitoras para melhor compreender os mecanismos de ação e de otimização da recuperação cardíaca.

Maximizar a sobrevida das CTMs transplantadas no microambiente avascular do coração isquêmico é crítico para atingir o mais alto grau de eficácia. Assim sendo, os pesquisadores experimentaram modificar geneticamente as CTMs com a adição de genes prósobrevida, sendo o melhor exemplo o estudo de Mangi et al. ${ }^{26}$ utilizando o gene Akt antiapoptótico. Isso resultou em sobrevida melhor e diferenciação de cardiomiócitos, com normalização quase completa dos parâmetros cardíacos funcionais. Apesar da evidência de que as ocasionais células-tronco progenitoras podem exibir fenótipos/genótipos cardiomiócito-específicos, incluindo alfa-actina, a cadeia pesada miosina, troponina- $\mathrm{T}$, conexina-43 e outros marcadores específicos de cardiomiócitos, a maioria das células transplantadas não parece se diferenciar em cardiomiócitos ou em nova vasculatura ${ }^{28,29}$. Elas podem, indiretamente, alterar o processo de remodelamento cardíaco pósinfarto, resultando na melhoria consistente do afinamento da parede, das propriedades hemodinâmicas e da função diastólica.

Melhora da função sistólica é raramente observada em estudos pré-clínicos de CTMs, provavelmente por causa da organização incompleta dos sarcômeros ${ }^{30}$. Ao contrário, após infarto do miocárdio, as células mesenquimais precursoras têm causado melhora significativa, tanto da função sistólica como da função diastólica; contudo, isso se deve possivelmente às diferenças nos perfis de secreção de citocina e nas propriedades arteriogênicas entre CTMs e células mesenquimais progenitoras ${ }^{14}$.

Estudos prévios usando células progenitoras endoteliais por administração intravenosa demonstraram neovascularização e angiogênese endógena de células progenitoras endoteliais após infarto do miocárdio ${ }^{21}$. Esses trabalhos sugeriram que as células-tronco podem diretamente fornecer o substrato para uma nova vasculatura e também secretar fatores que aumentam a angiogênese endógena. Recentemente, a secreção parácrina de fatores pró-angiogênicos e antiapoptóticos nas CTMs tem sido envolvida como fonte para estimular arteriogênese endógena, recuperando os cardiomiócitos hipertrofiados e o início do ciclo celular dos cardiomiócitos, e levando a melhoria funcional ${ }^{31,32}$. Entre as citocinas que contribuem para esses processos, incluem-se fator de crescimento do endotélio vascular (VEGF), fator de crescimento de fibroblastos (FGF), fator de crescimento derivado das plaquetas (PDGF), metaloproteinases de matriz, angiopoietina e outros.

Enquanto estudos de geneterapia com uma única superexpressão ou apenas um desses fatores por si não conseguiram induzir melhorias continuadas na função cardíaca, as células-tronco secretando múltiplos fatores em concentrações fisiologicamente otimizadas, com cada célula agindo como uma fábrica microfarmacêutica, são mais prováveis ${ }^{33,34}$.

Células progenitoras endoteliais são precursoras de músculo liso bem como progenitoras de CTMs, porém contêm propriedades fenotípicas/genotípicas e até pa- 
rácrinas diferentes das CTMs. Quando CTMs imunosselecionadas são diretamente injetadas 48 horas após infarto do miocárdio na zona limítrofe peri-infarto de camundongos, observa-se efeito dose-dependente no número de arteríolas, definidas como tendo camadas externas de músculo liso e positividade interna de fator de von Willebrand ${ }^{14}$. Esse aumento de três vezes na densidade arteriolar secundário a doses mais altas de células se correlaciona à melhoria média da fração de ejeção de $50 \%$ a $75 \%$ após duas e seis semanas, respectivamente, comparativamente às 48 horas iniciais pós-infarto (Figura 1). Quando foram usadas nesse modelo, as células mononucleares depletadas de CTMs não demonstraram diferença comparativamente aos controles tratados com solução salina. Esses achados foram confirmados em modelos maiores de ovinos com infarto do miocárdio. Existe clara diferença entre uma população de células-tronco derivada de medula adulta, tanto no que se refere às propriedades físicas como ao resultado funcional in vivo. Os estudos clínicos deverão claramente definir qual população de células está sendo usada, para, pelo menos de forma indireta, calibrar a eficácia dessas populações diferentes de células, bem como as várias vias de administração no homem.

\section{Administração de células-tronco mesenquimais para aplicações clínicas}

As CTMs são ligeiramente maiores que as célulastronco mesenquimais hematopoiéticas, porém em modelos de roedores e de animais maiores mantêm a capacidade de migrar para o miocárdio isquêmico depois da administração intravenosa pós-infarto. Para esse processo, a regulação do tempo é crítica e provavelmente depende do aumento do número de citocinas quimioatraentes, que persistem por apenas dois a três $\operatorname{dias}^{35}$. Estudos usando CTMs de rato que expressam betagalactosidase demonstraram que a migração e o subseqüente enxerto somente são evidentes logo após administração pós-infarto, enquanto a quimiotaxia para o miocárdio não está presente quando as células são administradas por via intravenosa duas semanas após infarto do miocárdio. Todavia, apesar de o enxerto de células ser detectado imediatamente, estudos usando


tículas de ferro após infarto do miocárdio demonstram que a maioria das células fica presa nos pulmões e que apenas a minoria delas chega com sucesso ao coração, quatro horas após a administração ${ }^{29}$. Mesmo com essas técnicas de marcação, é muito difícil

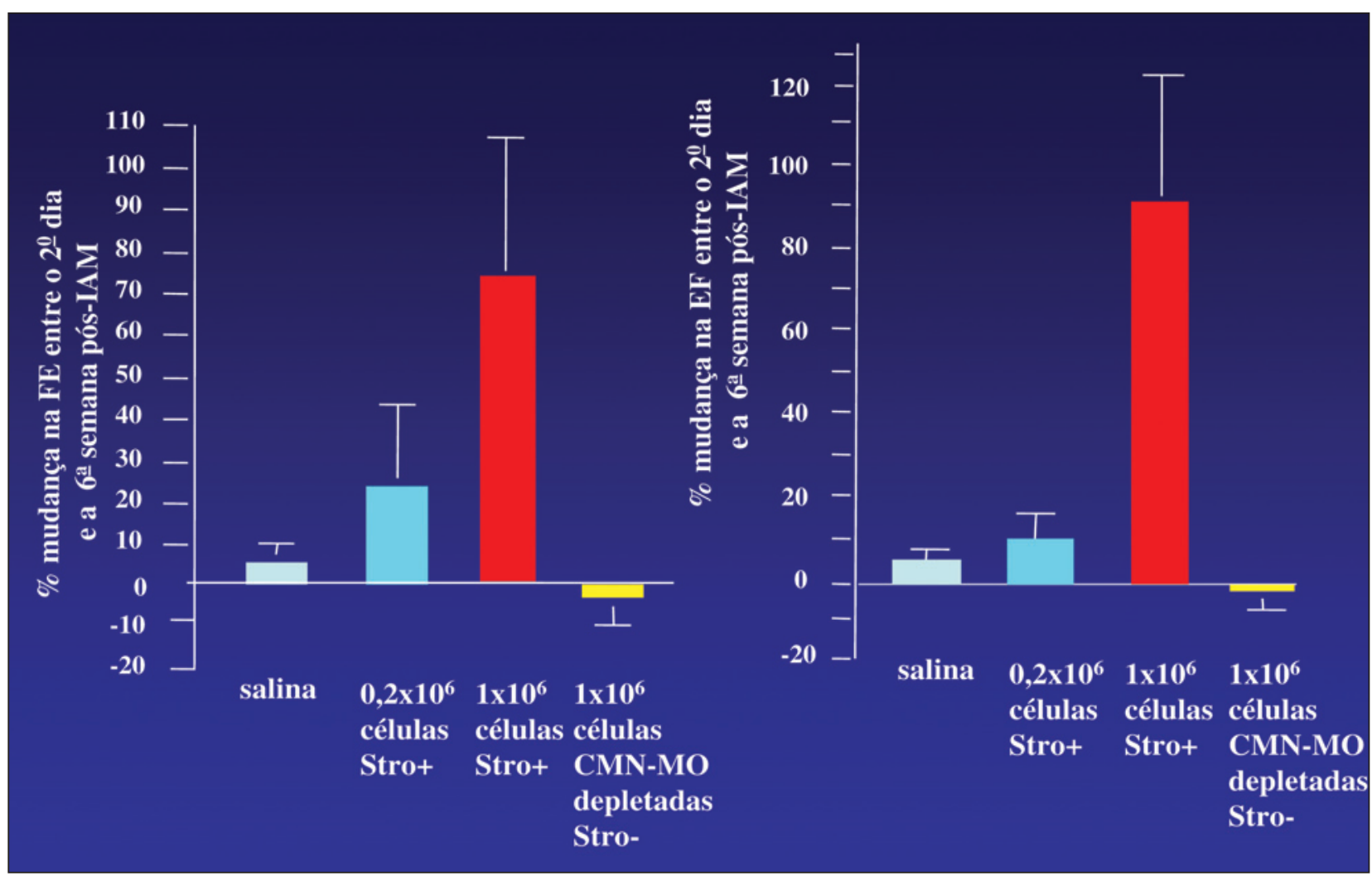

Figura 1 - A neovascularização miocárdica dependente de STRO-1 bright resulta na melhoria integral dos parâmetros da função miocárdica. Injeção de células $0,2 \times 10^{6}$ e $1 \times 10^{6}$ STRO- $1^{\text {bright }}$ resultou em melhoria dependente da dose, da fração de ejeção e encurtamento fracionário em duas a seis semanas, como medido pela ecocardiografia feita e analisada por um técnico cego para o tratamento, comparativamente a animais tratados com solução salina $(p<0,01)$ e animais tratados com células mononucleares $(p<0,01)$ de medula óssea fresca, privada de STRO-1. $\mathrm{CMN}-\mathrm{MO}=$ células mononucleares de medula óssea; $\mathrm{FE}=$ fração de ejeção; $\mathrm{EF}=$ encurtamento fracionário; $\mathrm{IAM}=$ infarto do miocárdio 
quantificar exatamente o número de células que chegam ao coração, ainda menos a viabilidade das células com o tempo. As atuais técnicas histopatológicas podem detectar essas células coradas, mas o coração deveria ser meticulosamente cortado em intervalos de cinco mícrons, com cada seção sendo verificada para um enxerto pareado, tornando tal processo árduo e abaixo do desejado. Os relatórios preliminares do ensaio intravenoso com CTMs alogênicas em pacientes com infarto agudo do miocárdio, que está sendo empreendido pela Osiris Therapeutics, sugerem que os pacientes têm tolerado, com segurança, a administração dessas CTMs e que não parece haver quaisquer eventos adversos agudos. Enquanto a terapia intravenosa representa a abordagem menos invasiva e menos dispendiosa, estratégias com o objetivo de localizar a administração e maximizar o enxerto poderão fornecer resultados clínicos melhores.

Embora células progenitoras endoteliais, células mononucleares da medula óssea e células progenitoras endoteliais selecionadas sejam administradas rotineiramente a pacientes pós-infarto do miocárdio por administração intracoronária, essa via de administração ainda precisa ser otimizada para as CTMs. Relatos prévios sugerem que as CTMs expandidas em cultura tendem a formar agregados precoces na circulação coronária, resultando em microinfartos e dispersão de enzima cardíaca. Isso pode decorrer de cultura com soro bovino, de viscosidade inerente das células ou de velocidades inadequadas do fluxo de administração. Todavia, até hoje, não podem ser administradas por via intracoronária ou intravenosa em moléstia cardíaca de isquemia crônica por falta de maior resposta ao estímulo das citocinas responsáveis pelo transporte para o miocárdio a partir do sistema circulatório. Dessa forma, devem ser utilizadas as estratégias que visam à injeção direta no músculo cardíaco.

Sistemas de administração por cateter endoventricular que mapeiam a zona limítrofe elétrica entre os miocárdios viável e necrótico oferecem a possibilidade de apontar com precisão para a região peri-infarto do coração, enquanto mantêm abordagem minimamente invasiva para o paciente. Sistemas como o NOGAMyostar têm sido usados com sucesso em muitos ensaios com células-tronco da medula óssea e estudos préclínicos com animais de grande porte ${ }^{36}$. Mesmo os cateteres endoventriculares "cegos", sem sistemas de mapeamento, são capazes de injetar as células diretamente na parede ventricular, apesar de sem a localização exata da injeção oferecida pelo sistema NOGA. Falta determinar se uma abordagem epicárdica cirúrgica supera a administração endoventricular e garante para o paciente o risco adicional de anestesia geral. Os produtos da próxima geração poderão incluir células-tronco com carregador ou arcabouço para assegurar enxerto e sobrevida inicial. Diversos ensaios clínicos programados para começar a inclusão em futuro próximo tentarão responder a essas perguntas, além de determinar a eficácia de uma variedade de CTMs ou células semelhantes a células mesenquimais progenitoras, a metodologia ideal de administração e o mais propício momento de administração.

\section{CONSIDERAÇÕES FINAIS}

A medula óssea adulta fornece uma fonte confiável e renovável de CTMs, que podem ser selecionadas, expandidas em cultura e caracterizadas para maximizar o potencial de diferenciação para as linhagens de osteócitos, condriócitos e adipócitos mesenquimais. Nessas células, faltam certos receptores co-estimulantes, que permitem sua evasão da rejeição imune in vivo e a capacidade de usar CTMs como um produto alogênico pronto. As CTMs, usadas em muitos modelos animais, têm demonstrado melhorar a função cardíaca após infarto do miocárdio e prevenir a progressão de insuficiência cardíaca. O mecanismo exato do reparo cardíaco ainda não foi esclarecido, mas provavelmente resulta da combinação de secreção parácrina de citocinas pró-arteriogênicas e antiapoptóticas ou tecido endógeno, bem como de diferenciação direta das CTMs em neovascularização ou cardiomiócitos. Para aplicações clínicas, a homogeneidade do produto e a reprodutibilidade lote a lote serão fundamentais para fins de regulamentação. Os métodos atualmente utilizados para isolar CTMs levam a alto grau de contaminação com células não-progenitoras, resultando em evolução inferior à desejada. As estratégias com o objetivo de selecionar células progenitoras endoteliais podem render uma população que reproduz apenas as células progenitoras, oferecendo produto mais eficiente e mais bem caracterizado. O uso de célulastronco alogênicas para moléstia cardíaca continua a ser uma área muito promissora e os protocolos clínicos voltados a investigar as vias e o momento de administração serão decisivos na maximização de seu benefício terapêutico.

\section{REFERÊNCIAS BIBLIOGRÁFICAS}

1. Wei H, Juhasz O, Li J, Tarasova YS, Boheler KR. Embryonic stem cells and cardiomyocyte differentiation: phenotypic and molecular analyses. J Cell Mol Med. 2005;9(4):804-17.

2. Kehat I, Gepstein L. Human embryonic stem cells for myocardial regeneration. Heart Fail Rev. 2003;8(3):229-36.

3. Simmons PJ, Gronthos S, Zannettino A, Ohta S, Graves S. Isolation, characterization and functional activity of human marrow stromal progenitors in hemopoiesis. Prog Clin Biol Res. 1994;389:271-80.

4. Ringden O, Uzunel M, Rasmusson I, Remberger M, Sundberg B, Lonnies $\mathrm{H}$, et al. Mesenchymal stem cells for treatment of therapy-resistant graft-versus-host disease. Transplantation. 2006;81(10):1390-7.

5. Schächinger $V$, Assmus B, Britten MB, Honold J, Lehmann $R$, Teupe C, et al. Transplantation of progenitor cells and regeneration enhancement in acute myocardial infarction: final one-year results of the TOPCARE-AMI Trial. J Am Coll Cardiol. 2004;44(8):1690-9.

6. Friedenstein AJ, Chailakhyan RK, Latsinik NV, Panasyuk AF, Keiliss-Borok IV. Stromal cells responsible for transfer- 
ring the microenvironment of the hemopoietic tissues. Cloning in vitro and retransplantation in vivo. Transplantation. 1974; 17(4):331-40.

7. Gronthos S, Zannettino AC, Hay SJ, Shi S, Graves SE, Kortesidis A, et al. Molecular and cellular characterisation of highly purified stromal stem cells derived from human bone marrow. J Cell Sci. 2003;116(Pt 9):1827-35.

8. Pittenger MF, Mackay AM, Beck SC, Jaiswal RK, Douglas R, Mosca JD, et al. Multilineage potential of adult human mesenchymal stem cells.Science. 1999;284(5411):143-7.

9. Friedenstein AJ, Petrakova KV, Kurolesova AI, Frolova GP. Heterotopic of bone marrow. Analysis of precursor cells for osteogenic and hematopoietic tissues. Transplantation. 1968;6(2):230-47.

10. Amado LC, Saliaris AP, Schuleri KH, St John M, Xie JS, Cattaneo S, et al. Cardiac repair with intramyocardial injection of allogeneic mesenchymal stem cells after myocardial infarction. Proc Natl Acad Sci USA. 2005;102(32):11474-9.

11. Gronthos S, Simmons PJ. The growth factor requirements of STRO-1-positive human bone marrow stromal precursors under serum-deprived conditions in vitro. Blood. 1995;85(4): 929-40.

12. Jiang $Y$, Jahagirdar $B N$, Reinhardt RL, Schwartz RE, Keene CD, Ortiz-Gonzalez XR, et al. Pluripotency of mesenchymal stem cells derived from adult marrow. Nature. 2002;418 (6893):41-9.

13. Jiang $Y$, Vaessen B, Lenvik $T$, Blackstad $M$, Reyes $M$, Verfaillie CM. Multipotent progenitor cells can be isolated from postnatal murine bone marrow, muscle, and brain. Exp Hematol. 2002;30(8):896-904.

14. Martens TP, See F, Schuster MD, Sondermeijer HP, Hefti MM, Zannettino A, et al. Mesenchymal lineage precursor cells induce vascular network formation in ischemic myocardium. Nat Clin Pract Cardiovasc Med. 2006;3(Suppl 1): S18-22.

15. Werner N, Kosiol S, Schiegl T, Ahlers P, Walenta K, Link $A$, et al. Circulating endothelial progenitor cells and cardiovascular outcomes. N Engl J Med. 2005;353(10):9991007.

16. Mahmud N, Pang W, Cobbs C, Alur P, Borneman J, Dodds $R$, et al. Studies of the route of administration and role of conditioning with radiation on unrelated allogeneic mismatched mesenchymal stem cell engraftment in a nonhuman primate model. Exp Hematol. 2004;32(5):494-501.

17. Le Blanc K, Rasmusson I, Sundberg B, Götherström C, Hassan M, Uzunel M, et al. Treatment of severe acute graftversus-host disease with third party haploidentical mesenchymal stem cells. Lancet. 2004;363(9419):1439-41.

18. Tse WT, Pendleton JD, Beyer WM, Egalka MC, Guinan EC. Suppression of allogeneic T-cell proliferation by human marrow stromal cells: implications in transplantation. Transplantation. 2003;75(3):389-97.

19. Le Blanc K, Tammik L, Sundberg B, Haynesworth SE, Ringdén O. Mesenchymal stem cells inhibit and stimulate mixed lymphocyte cultures and mitogenic responses independently of the major histocompatibility complex. Scand J Immunol. 2003;57(1):11-20.

20. Di Nicola M, Carlo-Stella C, Magni M, Milanesi M, Longoni PD, Matteucci P, et al. Human bone marrow stromal cells suppress T-lymphocyte proliferation induced by cellular or nonspecific mitogenic stimuli. Blood. 2002;99(10):3838-43.

21. Kocher AA, Schuster MD, Szabolcs MJ, Takuma S, Burkhoff D, Wang J, et al. Neovascularization of ischemic myocar- dium by human bone-marrow-derived angioblasts prevents cardiomyocyte apoptosis, reduces remodeling and improves cardiac function. Nat Med. 2001;7(4):430-6.

22. Schuster MD, Kocher AA, Seki T, Martens TP, Xiang G, Homma $S$, et al. Myocardial neovascularization by bone marrow angioblasts results in cardiomyocyte regeneration. Am J Physiol Heart Circ Physiol. 2004;287(2):H525-32.

23. Linke A, Müller P, Nurzynska D, Casarsa C, Torella D, Nascimbene A, et al. Stem cells in the dog heart are selfrenewing, clonogenic, and multipotent and regenerate infarcted myocardium, improving cardiac function. Proc Natl Acad Sci USA. 2005;102(25):8966-71.

24. Menasché $P$, Hagège $A A$, Vilquin JT, Desnos $M$, Abergel E, Pouzet B, et al. Autologous skeletal myoblast transplantation for severe postinfarction left ventricular dysfunction. J Am Coll Cardiol. 2003;41(7):1078-83.

25. Gojo S, Gojo N, Takeda Y, Mori T, Abe H, Kyo S, et al. In vivo cardiovasculogenesis by direct injection of isolated adult mesenchymal stem cells. Exp Cell Res. 2003;288(1):51-9.

26. Mangi AA, Noiseux $N$, Kong D, He H, Rezvani M, Ingwall JS, et al. Mesenchymal stem cells modified with Akt prevent remodeling and restore performance of infarcted hearts. Nat Med. 2003;9(9):1195-201.

27. Tomita S, Li RK, Weisel RD, Mickle DA, Kim EJ, Sakai T, et al. Autologous transplantation of bone marrow cells improves damaged heart function. Circulation. 1999;100(19 Suppl):II247-56.

28. Silva GV, Litovsky S, Assad JA, Sousa AL, Martin BJ, Vela $D$, et al. Mesenchymal stem cells differentiate into an endothelial phenotype, enhance vascular density, and improve heart function in a canine chronic ischemia model. Circulation. 2005;111(2):150-6.

29. Kraitchman DL, Heldman AW, Atalar E, Amado LC, Martin BJ, Pittenger MF, et al. In vivo magnetic resonance imaging of mesenchymal stem cells in myocardial infarction. Circulation. 2003;107(18):2290-3.

30. Pittenger MF, Martin BJ. Mesenchymal stem cells and their potential as cardiac therapeutics. Circ Res. 2004;95(1):9-20.

31. Gnecchi M, He H, Liang OD, Melo LG, Morello F, Mu H, et al. Paracrine action accounts for marked protection of ischemic heart by Akt-modified mesenchymal stem cells. Nat Med. 2005;11(4):367-8.

32. Gnecchi M, He H, Noiseux N, Liang OD, Zhang L, Morello $\mathrm{F}$, et al. Evidence supporting paracrine hypothesis for Aktmodified mesenchymal stem cell-mediated cardiac protection and functional improvement. FASEB J. 2006;20(6):661-9.

33. Kinnaird T, Stabile E, Burnett MS, Shou M, Lee CW, Barr $S$, et al. Local delivery of marrow-derived stromal cells augments collateral perfusion through paracrine mechanisms. Circulation. 2004;109(12):1543-9.

34. Kinnaird T, Stabile E, Burnett MS, Lee CW, Barr S, Fuchs $\mathrm{S}$, et al. Marrow-derived stromal cells express genes encoding a broad spectrum of arteriogenic cytokines and promote in vitro and in vivo arteriogenesis through paracrine mechanisms. Circ Res. 2004;94(5):678-85.

35. Kocher AA, Schuster MD, Bonaros N, Lietz K, Xiang G, Martens TP, et al. Myocardial homing and neovascularization by human bone marrow angioblasts is regulated by IL-8/Gro CXC chemokines. J Mol Cell Cardiol. 2006;40(4):455-64.

36. Perin EC, Dohmann HF, Borojevic R, Silva SA, Sousa AL, Mesquita CT, et al. Transendocardial, autologous bone marrow cell transplantation for severe, chronic ischemic heart failure. Circulation. 2003;107(18):2294-302. 